\title{
STANDAR KEKASARAN PERMUKAAN BIDANG PADA YOKE FLANGE MENURUT ISO R.1302 dan DIN 4768 DENGAN MEMPERHATIKAN NILAI KETIDAKPASTIANNYA
}

\author{
Bimbing Atedi dan Djoko Agustono \\ Puslit KIM dan SMTP-LIPI Serpong \\ Email: bimbing@kim.lipi.go.id
}

\begin{abstract}
ABSTRAKSI
Karakteristik suatu kekasaran permukaan memegang peranan penting dalam perancangan komponen mesin. Hal tersebut perlu dinyatakan dengan jelas misalnya dalam kaitannya dengan gesekan, keausan, pelumasan, ketahanan kelelahan, perekatan dua atau lebih komponen-komponen mesin. Yoke flange adalah merupakan bagian dari komponen otomotive pada transmisi penggerak roda belakang, yang salah satu bagian permukaan perlu memenuhi kekasaran dengan spesifikasi tertentu. Dimana permukaan komponen tersebut diperlukan suatu standar kekasaran permukaan yang ditetapkan dalam perancangan yaitu menurut standar ISO $R 1302$ dengan kode $N 8$ dengan nilai $R a=3,2 \mu m$. Sebagai master produk pengukuran terhadap nilai kekasaran permukaan perlu dilakukan pengukuran geometrik secara teliti dengan memperhatikan nilai ketidakpastian pengukurannya. Dengan analisis dari nilai ukurnya, diharapkan hasil dari proses produksi melalui pemesinan yang dilakukan, seluruh produknya dapat memenuhi persyaratan sesuai dengan spesifikasi teknis yang direncanakan.
\end{abstract}

Kata-kata kunci: kekasaran permukaan, yoke flange, ISO R 1302

\section{PENDAHULUAN}

Didalam pembahasan kekasaran permukaan suatu produk, pada umumnya perlu diperhatikan beberapa parameter yang akan diperlukan untuk menentukan nilai kekasarannya. Sebagai penentu kualitas produksi persyaratan kekasaran permukaan komponen mesin menurut standar ISO R 1302 dalam perancangan dimana parameter dicantumkan pada gambar teknik. Seperti pada kasus penelitian ini sebagai obyek pembahasan adalah nilai kekasaran permukaan dari sebuah Joke Flange, yaitu bagian dari komponen otomotive pada transmisi penggerak roda belakang yang berfungsi sebagai penghubung dari beberapa bagian komponen yang ada pada bagian tersebut seperti pada Gambar 1 .

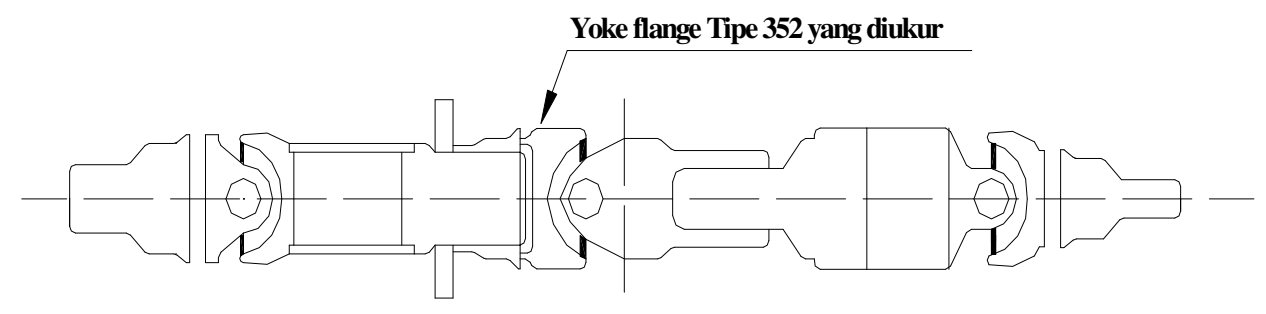

Gambar 1. Bagian Yoke Flange pada bagian transmisi 
Pada bagian tersebut permukaan dari Yoke Flange diperlukan standardisasi umum yang ditetapkan dalam ISO R 1302 yang mempunyai nilai kekasaran permukaan rata-rata $\mathrm{Ra}=3.2 \mu \mathrm{m}(\mathrm{N} 8)$ dengan hasil pekerjaan Milling Tegak yang mempunyai nilai kekasaran $\mathrm{Ra}$ antara 0.8 - $6.4 \mu \mathrm{m}$ (berdasarkan standar DIN 4768). Dari sampel produk hasil pengukuran dari 4 posisi kekasaran permukaan yang dianalisis nilai penyimpangan dan ketidakpastiannya, diharapkan semua produk memenuhi persyaratan masuk didalam batas toleransi yang diijinkan. Obyek pengukuran adalah Yoke Flange tipe 352, khusus digunakan untuk jenis kendaraan Mitsubishi colt diesel 100ps.

\section{DASAR TEORI}

Proses pemesinan kualitas kekasaran permukaan yang paling umum adalah harga kekasaran rata-rata aritmatik ( $\mathrm{Ra})$ yaitu, sebagai standar kualitas permukaan dari hasil pemotongan maksimum yang diijinkan. Dimana posisi Ra dan parameter kekasaran yang lain, bentuk profil, panjang sampel dan panjang pengukuran yang dilakukan oleh mein-mesin ukur kekasaran permukaan dapat dilihat seperti pada Gambar 2.

Menurut Standar ISO R 1302 "Method of Indicating surface Texture on Drawing'. Simbol persyaratan umum dituliskan seperti pada gambar 3 .

Sedangkan angka kekasaran permukaan roughness number dan panjang sample standard diklasifikasikan menjadi 12 angka kelas Tabel 1.

Spesifikasi, kekasaran permukaan untuk $\mathrm{R}_{\mathrm{a}}$ pada produk yoke flange tipe 352 adalah $\mathrm{R}_{\mathrm{a}}< \pm 3,2 \mu \mathrm{m}$, nilai kekasaran permukaan yang merupakan standar spesifikasi industri dari hasil operasi mesin Milling Tegak, dengan nilai maksimum 3.2 $\mu \mathrm{m}$ (N8) yang terdapat toleransi permukaan gambar teknis seperti pada Gambar 4.

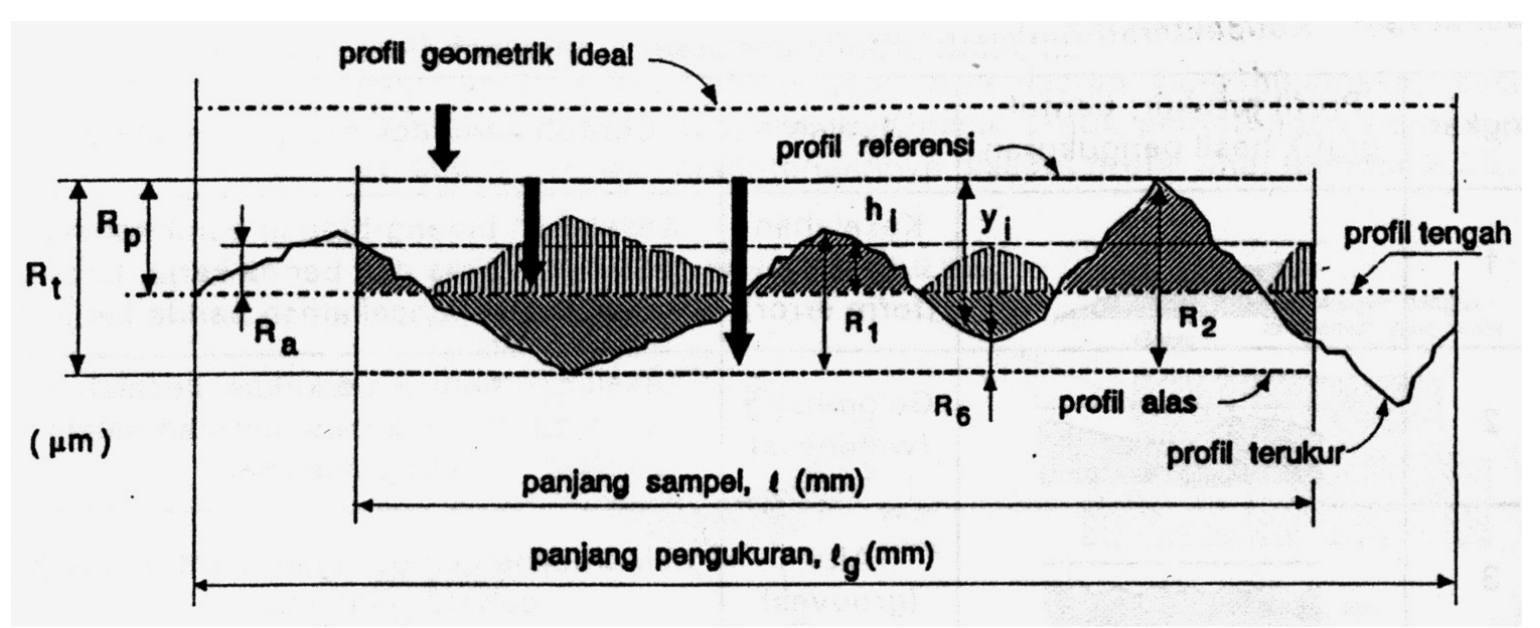

Gambar 2. Parameter-parameter dalam profil permukaan 


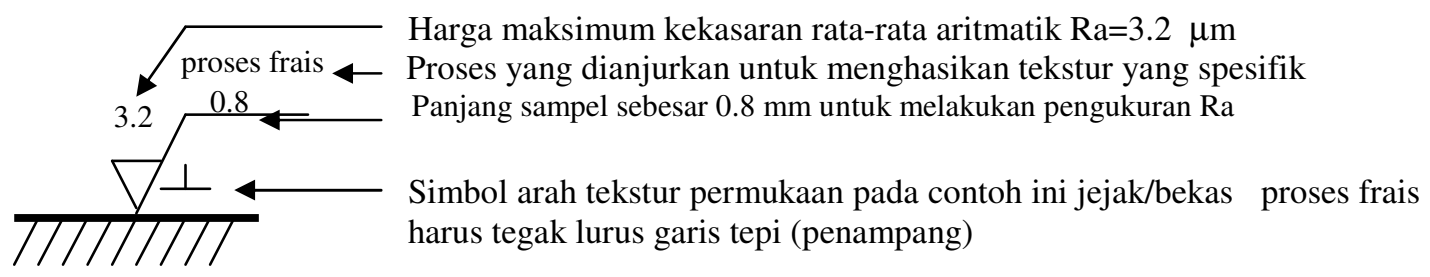

Gambar 3. Simbol pernyataan spesifikasi permukaan

Tabel 1. Angka kekasaran menurut ISO atau DIN 4763: 1981

\begin{tabular}{ccc}
\hline Kekasaran Ra $(\boldsymbol{\mu m})$ & Kelas kekasaran & Panjang Sampel $(\boldsymbol{\mu m})$ \\
\hline 50 & N12 & 8 \\
25 & N11 & \\
12,5 & N10 & 2.5 \\
6,3 & N9 & 0.8 \\
3,2 & N8 & \\
1,6 & N7 & \\
0,8 & N6 & \\
0,4 & N5 & 0.25 \\
0,2 & N4 & \\
0,1 & N3 & \\
0,05 & N2 & 0.08 \\
0,025 & N1 & \\
\hline
\end{tabular}

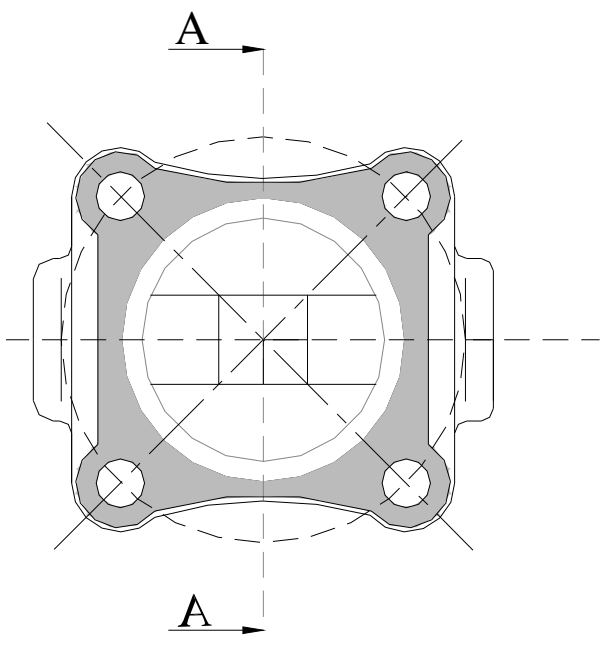

Permukaan Yoke Flange

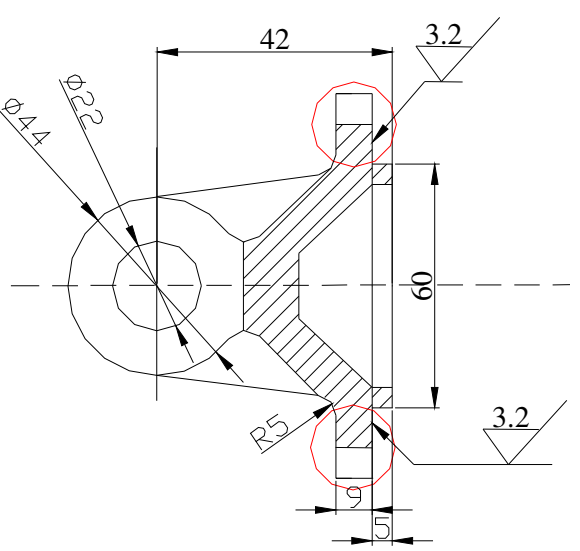

$\underline{\text { Potongan A - A }}$

Gambar 4. Yoke Flange Tipe 352 
Dalam proses pemesinan pada pengerjaan akhir untuk menentukan permukaan obyek dilakukan dengan proses Milling Tegak, menurut Tabel 2, kualitas permukaan yang dihasilkan dimana kekasaran permukaan rata-rata $\mathrm{Ra}$ yang distandarkan harus mencapai nilai antara $0,8-6,4 \mu \mathrm{m}$ (DIN 4768 Part 2)

\begin{tabular}{lcr}
\multicolumn{1}{c}{ Proses } & pengukuran & kekasaran \\
permukaan & dilakukan & $\begin{array}{r}\text { dengan } \\
\text { menggunakan }\end{array}$ \\
Mesin Ukur & Kekasaran \\
Permukaan & (Roughness & Measuring \\
Machine) Surfcom tipe 590A seperti pada \\
Gambar 5.
\end{tabular}

Tabel 2. Pekerjaan akhir proses pemesinan dan kekasaran permukaan Ra menurut standar DIN 4768 Part 2

\begin{tabular}{|c|c|c|c|c|c|c|}
\hline \multirow[t]{3}{*}{ PROSES } & \multicolumn{6}{|c|}{ KEKASARAN PERMUKAN, Ra $(\mu \mathrm{m})$} \\
\hline & \multirow[b]{2}{*}{6,3} & 05 & 0,1 & \multirow{2}{*}{0,2} & \multirow[t]{2}{*}{0,4} & \multirow[t]{2}{*}{3,2} \\
\hline & & 12.5 & & & & \\
\hline \multicolumn{7}{|l|}{ Superfinishing } \\
\hline \multicolumn{7}{|l|}{ Lapping } \\
\hline \multicolumn{7}{|l|}{ Polihing } \\
\hline \multirow{2}{*}{\multicolumn{7}{|c|}{ Honing }} \\
\hline & & & & & & \\
\hline \multicolumn{7}{|l|}{ Grinding } \\
\hline \multicolumn{7}{|l|}{ Boring } \\
\hline \multicolumn{7}{|l|}{ Turning } \\
\hline \multicolumn{7}{|l|}{ Drilling } \\
\hline \multicolumn{7}{|l|}{ Extruding } \\
\hline \multicolumn{7}{|l|}{ Drawing } \\
\hline \multicolumn{7}{|l|}{ Milling } \\
\hline \multirow{2}{*}{\multicolumn{7}{|c|}{ Shaping }} \\
\hline & & & & & & \\
\hline Planing & & & & & & \\
\hline
\end{tabular}

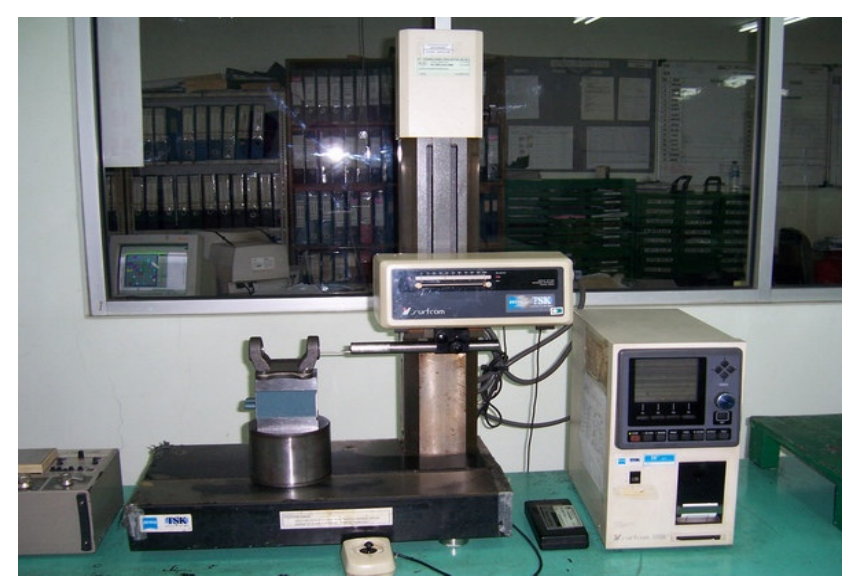

Gambar 5. Surfcom tipe 590A 
Tabel 3. Data Pengukuran kekasaran permukaan

\begin{tabular}{|c|c|c|c|c|c|c|}
\hline \multirow[t]{2}{*}{ Pengukuran } & \multirow[t]{2}{*}{ Posisi } & & \multicolumn{3}{|c|}{ Data Hasil Pengukuran } & \multirow{2}{*}{$\begin{array}{c}(\mu \mathrm{m}) \\
5\end{array}$} \\
\hline & & 1 & 2 & 3 & 4 & \\
\hline $\mathrm{R}_{\mathrm{a} 1}$ & 1 & 0.924 & 0.908 & 0.917 & 0.925 & 0.959 \\
\hline $\mathrm{R}_{\mathrm{a} 2}$ & 2 & 0.690 & 0.695 & 0.703 & 0.719 & 0.702 \\
\hline $\mathrm{R}_{\mathrm{a} 3}$ & 3 & 1.005 & 1.030 & 1.010 & 1.014 & 1.039 \\
\hline $\mathrm{R}_{\mathrm{a} 4}$ & 4 & 1.015 & 1.033 & 1.019 & 1.025 & 1.140 \\
\hline
\end{tabular}

Tabel 4. Data hasil pengukuran

\begin{tabular}{ccccc}
\hline Keterangan & Posisi Ra $1(\mu \mathrm{m})$ & Posisi R 2 $(\mu \mathrm{m})$ & Posisi Ra 3 $(\mu \mathrm{m})$ & Posisi Ra 4 $(\mu \mathrm{m})$ \\
\hline $\bar{q}$ & 0.9366 & 0.7108 & 1.0198 & 1.0464 \\
$(\mathrm{qk})$ & 0.0195 & 0.0109 & 0.0143 & 0.0426 \\
\hline
\end{tabular}

Keterangan :

- S(qk) : Standar deviasi

- $\bar{q} \quad$ : Nilai rata-rata penyimpangan

- $\mathrm{qk} \quad$ : Nilai penyimpangan

- $\mathrm{n} \quad$ : Jumlah pengukuran

\section{HASIL DAN PEMBAHASAN}

\section{Data pengukuran}

Nilai hasil pengukuran kekasaran permukaan yoke flange tipe 352 pada sampel, dengan pengukuran pada 4 posisi dengan masing-masing $5 \mathrm{x}$ pengukuran dapat dilihat tabel 3.

Perhitungan rata-rata penyimpangan kekasaran permukaan Yoke Flange

Untuk Ra Posisi 1

$\bar{q}=\frac{1}{n} \sum_{q k=1}^{n} q k$

$\bar{q}=\frac{q k 1+q k 2+q k 3+q k 4+q k 5}{n}$

$\bar{q}=\frac{0.924+0.908+0.917+0.925+0.959}{5}$

$\bar{q}=0.9366 \mu \mathrm{m}$
Keterangan :

$\bar{q} \quad$ : Nilai penyimpangan rata-rata

$\mathrm{qk}_{1}-\mathrm{qk}_{5}$ : Nilai pengukuran $1 \mathrm{sd} 5$

Untuk mencari nilai rata-rata penyimpangan kekasaran permukaan $R_{a}$ posisi 1, 2, 3 dan 4, pada sample selanjutnya dapat digunakan rumus yang sama

\section{Perhitungan simpangan baku ( $q k)$}

Untuk $R_{a}$ posisi 1

$$
\begin{aligned}
& s(q k)=\sqrt{\frac{1}{n-1} \sum_{k=1}^{n}(q k-\bar{q})^{2}} \\
& s(q k)=\sqrt{\frac{0.0014}{4}} \\
& s(q k)=0.01954 \mu \mathrm{m}
\end{aligned}
$$


Dari hasil perhitungan penyimpangan dan simpangan baku didapat hasil-hasil seperti yang dapat dilihat pada tabel 4 .

\section{Perhitungan ketidakpastian tipe A}

Ketidakpastian tipe A diambil dari standar deviasi terbesar $=0.0426 \mu \mathrm{m}$

Pada $\mathrm{R}_{\mathrm{a}}$ posisi 4

$\mathrm{U}_{\mathrm{A}}= \pm \frac{S(q k)}{\sqrt{n}}$

$\mathrm{U}_{\mathrm{A}}= \pm \frac{0.0426}{\sqrt{.5}}$

$\mathrm{U}_{\mathrm{A}}=0.0191 \mu \mathrm{m}$

Keterangan:

$\mathrm{U}_{\mathrm{A}} \quad$ : Ketidakpastian tipe A

$S(q k)$ : Diambil dari simpangan baku

terbesar

\section{Perhitungan Ketidakpastian Tipe B}

Ketidakpastian $\mathrm{B} 1 \quad\left(\mathrm{U}_{\mathrm{B} 2}\right)$ sertifikat kalibrasi mesin ukur

$$
\begin{aligned}
\mathrm{U}_{\mathrm{B} 1} & =0.025 \mu \mathrm{m} \\
& =0.025 \mu \mathrm{m}
\end{aligned}
$$

Ketidakpastian $\mathrm{B} 2\left(\mathrm{U}_{\mathrm{B} 1}\right)$ Resolusi alat ukur $($ pembesaran 50X) $=0.02 \mu \mathrm{m}$

$$
\begin{aligned}
\mathrm{U}_{\mathrm{B} 2} & =0,5 \times 0.02 / \sqrt{3} \mu \mathrm{m} \\
& =0.0057 \mu \mathrm{m}
\end{aligned}
$$

Ketidakpastian $\quad$ B3 $\left(\mathrm{U}_{\mathrm{B} 3}\right)$ mekanisme sistem mesin ukur

$$
\begin{aligned}
\mathrm{U}_{\mathrm{B} 3} & =0.02 / \sqrt{3} \mu \mathrm{m} \\
& =0.0115 \mu \mathrm{m}
\end{aligned}
$$

Ketidakpastian $\mathrm{B} 4\left(\mathrm{U}_{\mathrm{B} 4}\right)$ perbedaan suhu pengukuran $230 \mathrm{C}=0.5 \mu \mathrm{m}$

$$
\begin{aligned}
\mathrm{U}_{\mathrm{B} 4} & =0,5 / \sqrt{3} \mu \mathrm{m} \\
& =0.29 \mu \mathrm{m}
\end{aligned}
$$

\section{Perhitungan Ketidakpastian Gabungan}

$U c= \pm \sqrt{U_{A}^{2}+U_{B 1}^{2}+U_{B 2}^{2}+U_{B 3}^{2}}+U_{B 4} . .[4]$
$U c= \pm 0.0445 \mu \mathrm{m}$

\section{Perhitungan Ketidakpastian Terentang}

Derajat kebebasan untuk ketidakpastian didapat faktor cakupan $k$ sebesar 2 pada tingkat kepercayaan $95 \%$.

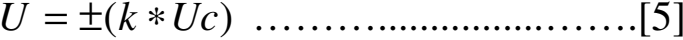

$$
\begin{aligned}
& U= \pm(2 * 0.0445) \\
& \mathrm{U}= \pm 0.089 \mu \mathrm{m}
\end{aligned}
$$

Ketidakpastian Pengukuran dari kekasaran permukaan $= \pm 0.089 \mu \mathrm{m}$.

\section{KESIMPULAN}

Dari hasil analisis penyimpangan pengukuran kualitas produk dapat disimpulkan bahwa:

1. Semua penyimpangan dari ke empat posisi rata-rata mempunyai nilai kekasaran permukaan $\mathrm{Ra}=\leq 1.231 \mu \mathrm{m}$ Sehingga masih didalam batas toleransi yang diizinkan, dengan Spesifikasi $\mathrm{Ra}$ yang direncanakan adalah antara $0.8 \mu \mathrm{m}-3.2 \mu \mathrm{m}$

2. Untuk nilai ketidakpastian gabungan didapat nilai sebesar $= \pm 0.0445 \mu \mathrm{m}$, dengan tingkat kepercayaan $95 \%$ dengan factor cakupan $=2$,

Ketidakpastian terentang $= \pm 0.089$ $\mu \mathrm{m}$.

3. Ditinjau dari nilai kekasaran permukaan menurut ISO B 1302, dari hasil proses Milling produk Yoke Flances, nilai penyimpangan dan ketidakpastian masih jauh dari batas toleransi, maka proses produksinya memenuhi persyaratan. 


\section{DAFTAR PUSTAKA}

Rochim, Taufiq, 2002, Spesifikasi, Metrologi dan Kontrol Kualitas Geometrik, Industrial Metrology Laboratory, Mechanical \& Production Engineering (MPE) Mesin, FTI - ITB.

Hobson, Tayor, 1998, Precision - Exploring Surface Texture, $3^{\text {rd }}$ edition March Standar ISO 1302 : 1996 dan Standar DIN 4768 : 1981 